\title{
PEMANFAATAN LIMBAH SEKAM PADI UNTUK CAMPURAN PUPUK BOKASHI DAN PEMBUATAN BIOBRIKET SEBAGAI BAHAN BAKAR NABATI
}

(The Utilization of Rice Husk Waste for Mixed Bokashi Fertilizer and Biobriket Making As Biofuels)

\author{
Noor Mirad Sari, Lusyiani , Khairun Nisa, M. Faisal Mahdie dan Diana Ulfah
}

\author{
Program Studi Kehutanan Fakultas Kehutanan \\ Universitas Lambung Mangkurat \\ Jl. Ahmad Yani Km. 36 Banjarbaru, Kalimantan Selatan
}

email: noormirad sari@yahoo.co.id

\begin{abstract}
The rice husk waste often becomes a problem for people in Tatah Makmur district. The mountanous of stack of rice husk has not been utilized by farmers as a useful material. The science activities for the people aimed to provide knowledge about the utilization of rice husk waste into charcoal husk, biobriket, and bokashi. The target people of this program are Kelompok Tani Bina Desa Jaya RT. 07 and Yasinan Group RT. 06 in Tatah Makmur district. The types of outcomes generated through the science activities for the people are biobriket and bokashi. The socialization, counseling and training activities were held from May to October 2015 in Pemangkih Village, Tatah Makmur district, South Kalimantan. The people in the village enthusiastically participated in extension activities as they gained knowledge about the making of bokashi and biobriket so that it can reduce dependence on chemical fertilizers and wood fuels. The science activities for this people can solve the problems of the farmers in the utilization of rice husk waste and at the same time can overcome the farmers' difficulties in obtaining organic fertilizer.
\end{abstract}

Keywords: rice husk waste, bokashi, biobriket

\section{Abstrak}

Limbah kulit beras sering menjadi masalah tersendiri bagi masyarakat di Kecamatan Tatah Makmur. Tumpukan sekam padi yang menggunung belum dimanfaatkan oleh petani sebagai bahan yang bermanfaat. Kegiatan Ipteks bagi Masyarakat ini bertujuan memberikan ilmu pengetahuan tentang pemanfaatan limbah sekam padi menjadi arang sekam, biobriket, dan bokashi. Khalayak sasaran program ini adalah Kelompok Tani Bina Desa Jaya Rt. 07 dan Kelompok Yasinan Rt. 06 di Kecamatan Tatah Makmur. Jenis luaran yang dihasilkan melalui kegiatan Ipteks bagi Masyarakat adalah biobriket dan bokashi. Kegiatan sosialisasi, penyuluhan dan pelatihan dilaksanakan pada bulan Mei sampai bulan Oktober 2015 di Desa Pemangkih, Kecamatan Tatah Makmur Kalimantan Selatan. Masyarakat di desa tersebut antusias mengikuti kegiatan penyuluhan karena mereka mendapatkan pengetahuan tentang pembuatan bokashi dan biobriket sehingga mengurangi ketergantungan terhadap pupuk kimia dan bahan bakar kayu. Kegiatan Ipteks bagi masyarakat ini dapat memecahkan masalah petani dalam hal pemanfaatan limbah sekam padi dan sekaligus mengatasi kesulitan petani dalam memperoleh pupuk organik.

Kata Kunci : Limbah sekam padi, bokashi, biobriket 


\section{PENDAHULUAN}

\section{Analisa Situasi}

Kecamatan Tatah Makmur (Gambut) Kalimantan Selatan merupakan salah satu lumbung beras utama Kalimantan Selatan. Menurut Wakil Bupati Banjar Ahmad Fauzan Saleh pada saat safari Ramadhan di Kecamatan Tatah Makmur, Kabupaten Banjar pada tahun 2012 dengan luas lahan 74,425 hektar menghasilkan beras sekitar 284.806 ton. Produksi beras pada tahun 2012 lebih besar jika dibandingkan pada tahun 2011 yang hanya sekitar 244.800 ton. (http://www.antarakalsel.com)

Sekam padi merupakan lapisan keras yang meliputi kariopsis, terdiri daribelahan lemma dan palea yang saling bertautan, umumnya ditemukan di areal penggilingan padi. Dari proses penggilingan padi, biasanya diperoleh sekam 20 $30 \%$, dedak $8-12 \%$, dan beras giling $50-$ $63,5 \%$ dari bobot awal gabah. Sekam memiliki kerapatan jenis bulk density $125 \mathrm{~kg} / \mathrm{m} 3$, dengan nilai kalori $1 \mathrm{~kg}$ sekam padi sebesar 3300 k.kalori dan ditinjau dari komposisi kimiawi, sekam mengandung karbon (zat arang) 1,33\%, hydrogen $1,54 \%$, oksigen 33,645 , dan Silika $\left(\mathrm{SiO}_{2}\right) 16,98 \%$, artinya sekam dapat dimanfaatkan sebagai bahan baku industri kimia dan sebagai sumber energi panas untuk keperluan manusia (Sipahutar, 2012).

Besarnya limbah yang dihasilkan dari proses penggilingan padi menjadi masalah yang harus dipikirkan jalan keluarnya karena ternyata setelah di buat bokashi, sekam padi memberikan banyak manfaat bagi pertumbuhan tanaman. Bokashi adalah pupuk kompos yang dibuat dengan proses peragian bahan organik dengan
EM4 (Effective Microorganime 4) atau disebut dengan hasil proses fermentasi, pupuknya dinamakan pupuk EM4. EM4 (Effective Microorganime 4) mengandung mikroorganisme fermentasi dan sintetik yang terdiri dari bakteri asam laktat (Lactobachilus sp.), bakteri fotosintetik (Rhodopseudomonas sp.), Actinomycetes sp., Streptomyces sp., dan ragi (Marsono dan Sigit, 2005). Keunggulan penggunaan EM4 adalah pupuk organik dapat dihasilkan dalam waktu yang lebih cepat dibandingkan dengan cara konvensional. Penelitian Suji (2014) menunjukkan pupuk bokashi sekam padi berstimulator EM4 berpengaruh nyata terhadap pertumbuhan vegetatif dan generatif tanaman jagung manis (Zea mays Saccaharata). Perlakuan pupuk bokashi sekam padi berstimulator EM4 dengan dosis $45 \mathrm{Ton} / \mathrm{ha}(21,60 \mathrm{Kg} /$ Petak $=4,5 \mathrm{~kg} / \mathrm{m} 2)$ memberikan pengaruh terbaik terhadap pertumbuhan dan hasil jagung manis (Zea mays Saccarata).

Energi merupakan suatu komponen kebutuhan hidup yang sangat penting. Menipisnya persediaan minyak bumi menjadi permasalahan besar dalam krisis energi, sehingga diperlukan solusi untuk membuat bahan bakar nabati yang bisa diperbaharui. Sudah saatnya Indonesia mengurangi ketergantungan terhadap bahan bakar fosil dengan mengembangkan sumber energi alternatif terbarukan. Pengembangan bioenergi diharapkan dapat mensubstitusi kebutuhan BBM di Indonesia.

Pemanfaatkan limbah sekam padi dapat menyelesaikan beberapa permasalahan sekaligus yaitu petani dapat memanfaatkan limbah sekam padi menjadi arang sekam, biobriket dan bokashi. 
Selain itu petani dapat membuat sendiri bokashi dan bahan bakar alternatif ini sehingga dapat mengurangi pengeluaran rumah tangga petani serta dapat menambah pendapatan mereka dengan menjual briket arang sekam dan bokashi tersebut.

\section{Permasalahan}

Kecamatan Tatah Makmur merupakan salah satu kecamatan penghasil beras di Kalimantan, Selatan sehingga pada saat pasca panen terdapat limbah sekam padi hasil dari proses penggilingan padi menjadi beras dalam jumlah berlimpah. Selama ini masyarakat Desa Pemangkih Kecamatan Tatah Makmur belum memanfaatkan limbah sekam padi menjadi produk yang bermanfaat, hal tersebut disebabkan minimnya pengetahuan petani dalam hal pemanfaatan limbah sekam padi serta belum adanya transfer iptek kepada petani tentang pembuatan biobriket dan bokashi dari limbah tersebut. Berdasarkan permasalahan tersebut maka perlu dilaksanakan kegiatan Ipteks bagi Masyarakat sehingga petani mampu memanfaatkan limbah sekam padi menjadi energi alternatif (biobriket) dan bokashi yang dapat dipergunakan sebagai pupuk bagi tanah pertanian.

\section{Tujuan}

Tujuan kegiatan pengabdian kepada masyarakat ini adalah memberikan pendampingan berupa penyuluhan dan pelatihan tentang pemanfaatan limbah pertanian berupa sekam padi menjadi bahan bakar (biobriket) dan bokashi dengan teknologi sederhana.

\section{METODE PELAKSANAAN}

\section{Waktu dan Tempat}

Kegiatan Ipteks bagi masyarakat pemanfaatan limbah sekam padi untuk campuran pupuk bokashi dan pembuatan biobriket sebagai bahan bakar nabati dilaksanakan sejak bulan Mei sampai bulan Agustus 2015. Kegiatan ini dilaksanakan di Desa Pemangkih RT. 6 dan RT. 7, Kecamatan Tatah Makmur Kabupaten Banjar Kalimantan Selatan.

\section{Sasaran Kegiatan}

Khalayak sasaran program ini adalah masyarakat yang belum produktif secara ekonomis tetapi berhasrat kuat menjadi wirausahawan. Mitra I adalah Kelompok Tani Bina Desa Jaya Rt. 07 yang berlokasi di Desa Pemangkih Kecamatan Tatah Makmur. Mitra II adalah Kelompok Yasinan Rt. 06 di Kecamatan Tatah Makmur.

\section{METODE KEGIATAN}

Metode kegiatan Ipteks bagi Masyarakat dilaksanakan melalui tahapan :

1. Sosialisasi Program

Pemberian informasi dan pengetahuan tentang manfaat limbah sekam padi yang dapat dibuat pupuk bokashi sehingga mengurangi limbah pertanian sekaligus mampu menyuburkan sawah dan briket arang sekam (biobriket) yang dapat menjadi alternatif bahan bakar pengganti minyak tanah.

2. Penyuluhan dan Pelatihan

Kegiatan pelatihan ketrampilan diberikan kepada masyarakat Desa Pemangkih agar mampu menyerap pengetahuan yang 
diberikan oleh tim pelaksana IbM. Pelatihan yang diberikan meliputi :

a) Pembuatan bokashi menggunakan campuran limbah sekam padi, jerami, hijauan dan dedak.

b) Proses pengarangan limbah sekam padi menjadi arang sekam

c) Pembuatan briket arang sekam dan proses cetak briket

\section{Pendampingan Kelompok Tani}

Pendampingan kelompok tani dilakukan setelah kegiatan pelatihan, dalam rangka pengembangan usaha petani dalam pemanfaatan limbah sekam padi menjadi produk biobriket dan bokashi. Pendampingan dilakukan secara berkala sehingga meningkatkan kemampuan petani dalam menghasilkan produk tersebut.

\section{HASIL DAN PEMBAHASAN}

Kegiatan Pengabdian kepada masyarakat berupa Ipteks bagi Masyarakat pembuatan bokashi berbahan sekam padi dan jerami serta pembuatan biobriket dilaksanakan di Desa Pemangkih, Kecamatan Tatah Makmur. Berdasarkan peraturan daerah Kabupaten Banjar Nomor 06 Tahun 2008 Kecamatan Tatah Makmur merupakan kecamatan pemekaran dari kecamatan Hertak Hanyar. Ibukota Kecamatan berkedudukan di Desa Tampang Awang dengan nama Ibukota Kecamatan adalah "Tatah Makmur". Wilayah Kecamatan Tatah Makmur meliputi jumlah penduduk 10.579 Jiwa, luas wilayah $34,47 \mathrm{Km}$ dan jumlah kelurahan/Desa adalah 13 (tiga belas) desa.
Masyarakat Desa Pemangkih memberikan respon positif terhadap kegiatan pembuatan bokashi dan biobriket yang dilaksanakan oleh tim pelaksana. Masyarakat yang hadir berjumlah 50 (lima puluh) orang beserta aparat desa setempat yaitu Ketua RT. 6 Bapak Biirni, Ketua RT. 7 Bapak Busiri serta ketua kelompok tani 'Bina Desa Jaya" Bapak Jamhari. Pada kegiatan penyuluhan dan pelatihan dilakukan pendampingan cara membuat membuat arang sekam, pupuk bokashi dan biobriket.

Gambar 1. Kegiatan Penyuluhan

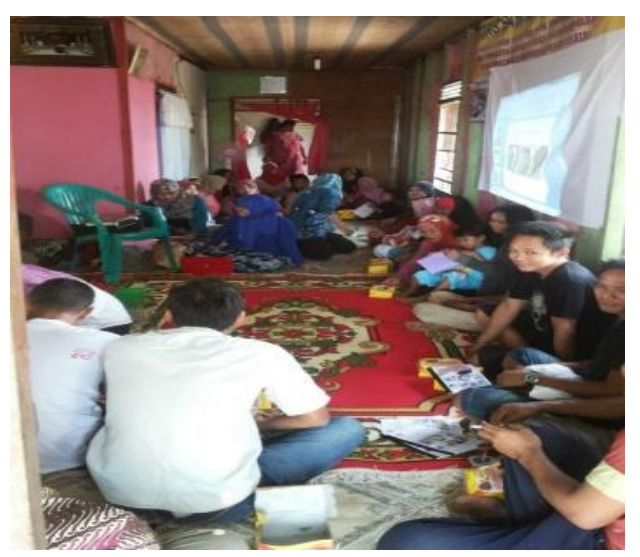

Kegiatan Pengabdian kepada masyarakat yang dilaksanakan pada petani yang tergabung dalam "Kelompok Yasinan" RT. 6 dan kelompok tani "Bina Desa Jaya" RT. 7 dianggap tepat sasaran karena selama ini mereka belum pernah memanfaatkan sekam padi menjadi bokashi dan briket arang, padahal di desa tersebut terdapat limbah sekam padi dalam jumlah besar. produk.

Pemanfaatan lahan gambut untuk pertanian di Indonesia sudah dimulai sejak ratusan tahun yang lalu oleh petani Banjar di Kalimantan (Sarwani dan Thamrin dalam Noor, 2001). Tingkat kesuburan lahan gambut rendah sehingga diperlukan pemberian pupuk organik seperti bokashi. Pemanfaatan bokashi sekam 
padi dan jerami dapat menghemat pengeluaran petani dan mengurangi ketergantungan terhadap pupuk kimia.

Bahan-bahan yang dibutuhkan untuk pembuatan bokashi yaitu jerami dan sekam padi tersedia melimpah di Desa Pemangkih. Selain jerami dan sekam padi, bahan lain yang dicampurkan dalam bokashi adalah dedak, karena kandungan zat gizinya sangat baik untuk mikroorganisme. Bokashi jerami dan sekam padi sangat baik digunakan untuk melanjutkan proses pelapukan mulsa dan bahan organik lainnya dilahan pertanian. Bokashi jerami dan sekam padi juga sesuai untuk diaplikasikan di lahan sawah.

Komposisi pupuk bokashi yang digunakan dalam pembuatan bokashi adalah sebagai berikut
a. Jerami : 500 gram
b. Sekam : 500 gram
c. Dedak : 25 gram
d. Hijauan : 100 gram
e. EM4 : $10 \mathrm{ml}$
f. Gula : $10 \mathrm{gr}$
g. Air : $500 \mathrm{ml}$

Pupuk bokashi yang telah dibuat dapat disimpan selama 1 tahun setelah dikeringkan dengan cara dijemur sampai kering. Pupuk yang telah kering setelah dijemur kemudian dikemas dalam kantong plastik. Bokashi dapat disebar merata di atas permukaan tanah dengan dosisi 3 - 4 genggam persatu meter persegi (150 - 200 gram), untuk tanah yang kurang subur dapat diberikan lebih banyak lagi, sedangkan untuk tanah yang cukup rusak yang disebabkan porositas tanah yang jelek maka untuk mengembalikan kondisi tanah menjadi baik diperlukan bokashi sebesar kurang lebih 5 ton/ha.
Cara mencampurkan bokashi dapat dilakukan dengan cara tanah dicangkul atau dibajak. Pada tanah persawahan pemberian bokashi dilakukan sebelum pembajakan. Pemberian pupuk bokashi untuk menyuburkan tanah dan meningkatkan pertumbuhan padi dapat dilakukan kembali ketika padi berumur 14 hari dan 1 bulan. Pada prinsipnya aplikasi dapat dilakukan pada saat pengolahan tanah sebagai penutup lubang tanam, untuk lahan kering pupuk bokashi dapat ditaburkan sebelum tanam. Setelah bokashi disebar kemudian disemprot 2 cc EM4 /liter air ke dalam tanah, 1 minggu kemudian bibit siap ditanam. Pelatihan pembuatan pupuk bokashi dilakukan agar masyarakat yang tergabung dalam kelompok Yasinan RT. 7 dan Kelompok Tani Bina Desa Jaya mengetahui secara langsung proses pembuatan bokashi serta komposisi bahan yang digunakan

Gambar 2. Pelatihan pembuatan Bokashi
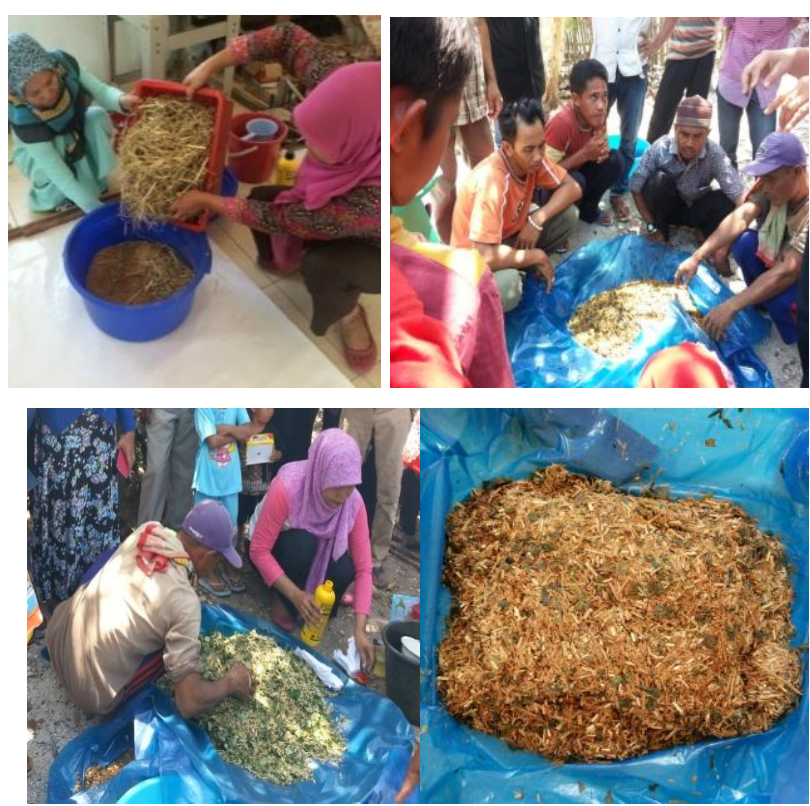
Masyarakat di Desa Pemangkih menyatakan mereka selama ini membeli pupuk kimia yang harganya relatif mahal. Pemanfaatan sekam dan jerami padi menjadi pupuk bokashi dapat mengurangi ketergantungan masyarakat terhadap pupuk kimia yang mempunyai dampak negatif terhadap lingkungan dan kesehatan. Aplikasi pupuk bokashi di lahan pertanian dapat membantu memperbaiki struktur fisik, kimia dan biologi tanah. Manfaat lain pupuk bokashi adalah sebagai berikut :

1) Memberikan nutrisi bagi tanaman

2) Meningkatkan kapasitas tukar kation

3) Menambah kemampuan tanah menambah air

4) Meningkatkan aktivitas biologi tanah

5) Meningkatkan $\mathrm{pH}$ pada tanah masam

6) Meningkatkan unsur hara mikro

7) Tidak menimbulkan masalah bagi lingkungan

Biobriket di definisikan sebagai bahan bakar yang berwujud padat dan berasal dari sisasisa bahan organik yang telah mengalami proses pemampatan dengan daya tekan tertentu. Pemanfaatan biobriket sebagai energi alternatif merupakan langkah tepat. Biobriket dapat menggantikan penggunaan kayu bakar yang mulai meningkat konsumsinya dan berpotensi merusak ekologi hutan. Selain itu harga biobriket relatif murah dan terjangkau oleh masyarakat (Hambali, 2007).

Proses pembuatan briket sekam padi untuk kegiatan di mulai dengan proses pengarangan atau pembakaran sekam padi menjadi arang sekam. Proses pengarangan dilakukan agar menghasilkan arang sekam yang selanjutnya akan di proses menjadi biobriket arang sekam.
Waktu yang diperlukan jika proses pengarangan sekam menggunakan alat pengarangan berupa drum adalah 5 - 6 jam tetapi jika menggunakan alat pengarangan sederhana berupa cerobong hanya diperlukan waktu singkat. Alat pengarangan sederhana berupa cerobong tersebut dapat diaplikasikan di masyarakat karena dapat dibuat dengan memanfaatkan kaleng bekas. Proses pengarangan sekam dapat dilihat pada Gambar 3.

Gambar 3. Pelatihan pembuatan arang sekam

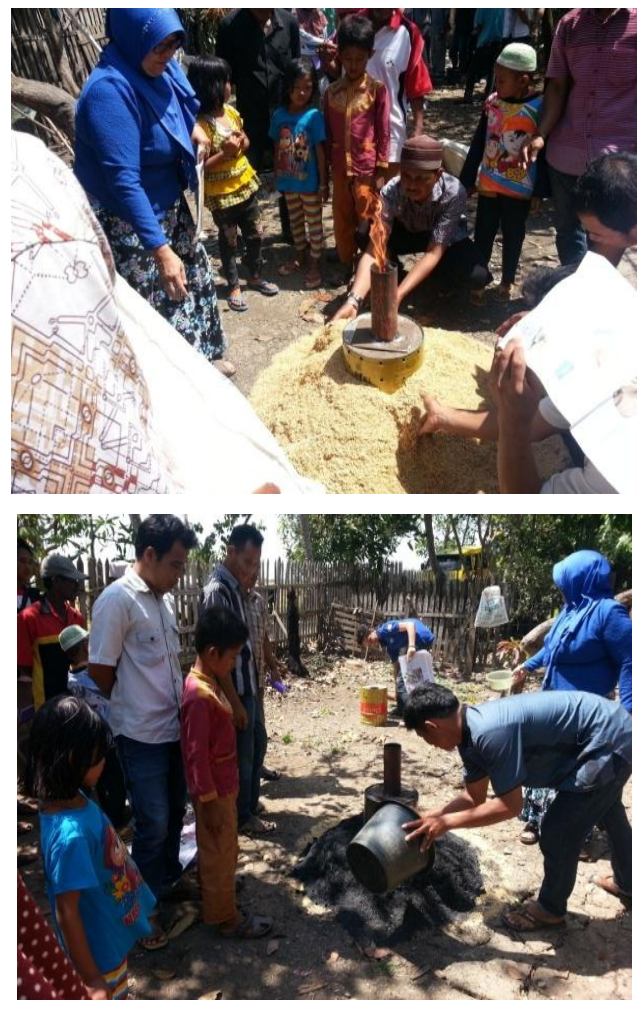

Pembuatan briket arang sekam dilakukan setelah dihasilkan arang sekam dari proses pengarangan. Arang sekam diremas kemudian dicampur dengan tepung kanji yang telah dididihkan terlebih dahulu, di aduk hingga tercampur merata. Arang sekam dan tepung kanji yang telah tercampur merata selanjutnya dimasukkan ke dalam cetakan dan dicetak 
menggunakan alat cetak briket sederhana. Jika telah dihasilkan briket arang maka proses selanjutnya adalah proses pengeringan dengan cara dijemur memanfaatkan sinar matahari.

Pembuatan briket arang sekam menggunakan komposisi tertentu tergantung dari banyak sedikitnya briket yang akan dibuat. Komposisi arang sekam sebanyak 1 (satu) kg, air $1665 \mathrm{ml}$ dan tepung kanji 250 gram akan menghasilkan 38 buah briket arang sekam padi. Satu buah briket dengan berat berkisar antara 18,5 - 25,1 gram mampu bertahan menyala selama 30 menit.

Gambar 4. Pelatihan pembuatan briket arang sekam
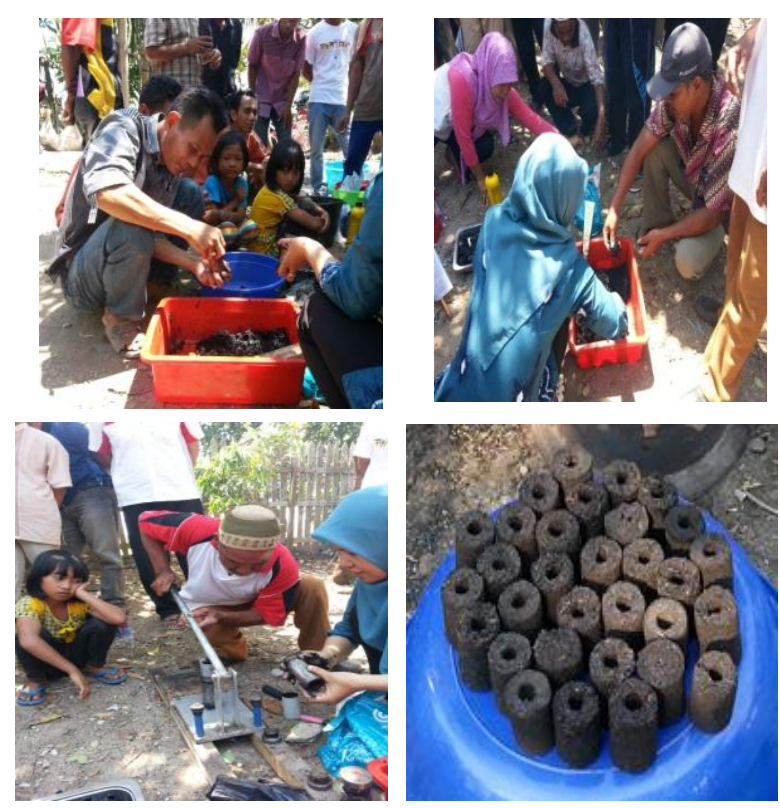

Tingginya minat masyarakat mengikuti kegiatan penyuluhan dan pelatihan karena selama ini di desa mereka jarang dilakukan kegiatan penerapan Ipteks bagi Masyarakat. Menurut Bapak Jamhari selama ini kelompok tani "Bina Desa Jaya" hanya berfungsi sebagai pengumpul beras untuk dijual kembali. Penyuluhan dan pelatihan yang disampaikan oleh tim pelaksana memacu semangat mereka untuk memanfaatkan dan mengembangkan limbah padi (sekam padi dan jerami) menjadi produk pupuk bokashi dan biobriket yang mempunyai nilai ekonomis dan sekaligus dapat dimanfaatkan masyarakat dalam kehidupan sehari-hari. Kegiatan pendampingan oleh tim pelaksana dilaksanakan setelah kegiatan penyuluhan dan pelatihan dalam rangka keberlanjutan program penerapan Ipteks bagi masyarakat

Gambar 5. Kegiatan pendampingan

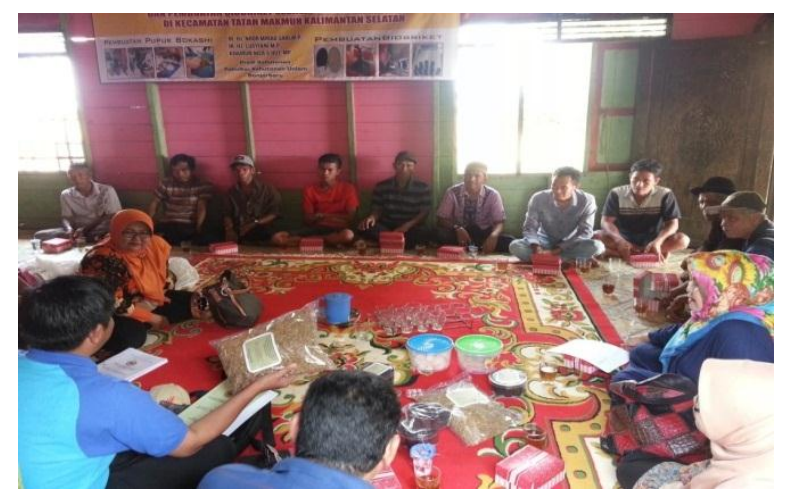

Gambar 6. Produk yang telah dikemas
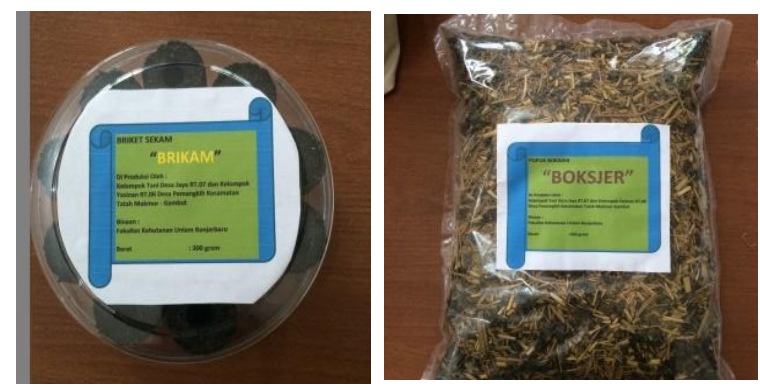

Melalui kegiatan Ipteks bagi masyarakat petani yang menjadi mitra yaitu Kelompok Yasinan RT. 6 dan Kelompok Tani "Bina Desa Jaya" mampu mengatasi beberapa masalah yang selama ini mereka hadapi. Tabel 1 menunjukkan beberapa masalah yang selama ini dihadapi oleh petani di Desa Pemangkih dan solusi yang telah diberikan oleh tim pelaksana kegiatan Ipteks bagi Masyarakat. 
Tabel Permasalahan Petani dan Pemecahan Masalah

\begin{tabular}{|c|c|c|}
\hline No & $\begin{array}{l}\text { Permasalahan } \\
\text { Petani }\end{array}$ & Pemecahan Masalah \\
\hline 1 & $\begin{array}{l}\text { Kurangnya } \\
\text { pengetahuan } \\
\text { petani tentang } \\
\text { manfaat limbah } \\
\text { pertanian }\end{array}$ & $\begin{array}{l}\text { Petani mendapatkan } \\
\text { pengetahuan tentang } \\
\text { manfaat limbah sekam } \\
\text { padi yang dapat dibuat } \\
\text { bokashi dan biobriket }\end{array}$ \\
\hline 2 & $\begin{array}{l}\text { Melimpahnya } \\
\text { limbah } \\
\text { pertanian } \\
\text { (sekam padi } \\
\text { dan jerami) di } \\
\text { Desa } \\
\text { Pemangkih } \\
\text { RT.6 dan RT.7 } \\
\text { Kecamatan } \\
\text { Tatah Makmur }\end{array}$ & $\begin{array}{l}\text { Pelatihan cara } \\
\text { mengarangkan sekam } \\
\text { padi menggunakan alat } \\
\text { pengarang sekam } \\
\text { sederhana yang dapat } \\
\text { dibuat oleh petani } \\
\text { pelatihan cara } \\
\text { membuat limbah } \\
\text { pertanian (sekam padi) } \\
\text { menjadi biobriket } \\
\text { pelatihan cara /mencetak } \\
\text { membuat mengunakan } \\
\text { biobriket mengunat } \\
\text { alat cetak biobriket }\end{array}$ \\
\hline 3 & $\begin{array}{l}\text { Kesulitan petani } \\
\text { mendapatkan } \\
\text { pupuk organik } \\
\text { yang dapat } \\
\text { menyuburkan } \\
\text { tanah }\end{array}$ & $\begin{array}{l}\text { 1. Pelatihan cara } \\
\text { membuat limbah } \\
\text { pertanian (sekam padi } \\
\text { dan jerami) menjadi } \\
\text { menjadi bokashi } \\
\text { 2. Penyuluhan } \\
\text { pemanfaatan bokashi } \\
\text { hasil kegiatan lbM } \\
\text { yang dapat ditanami } \\
\text { benih sayuran dan } \\
\text { padi }\end{array}$ \\
\hline
\end{tabular}

\section{KESIMPULAN}

Melalui kegiatan Ipteks bagi masyarakat "Pemanfaatan limbah sekam padi untuk campuran pupuk bokashi dan pembuatan biobriket sebagai bahan bakar nabati" diperoleh kesimpulan:

1. Kegiatan Ipteks bagi masyarakat dapat memecahkan masalah petani dalam hal pengelolaan limbah pertanian dan kesulitan dalam memperoleh pupuk organik.
2. Petani yang menjadi mitra kegiatan mampu membuat bokashi dan briket arang dari limbah sekam padi

3. Luaran yang dihasilkan berupa biobriket dan bokashi dengan menggunakan teknologi yang sederhana, murah, dan mudah dilakukan.

\section{DAFTAR PUSTAKA}

www.antarakalsel.com. Banjar Tetap Lumbung Padi. Diakses tanggal 22 April 2014. http://www.antarakalsel.com/berita/12384/b anjar-tetap-lumbung-padi.

www.alamtani.com, 2012. Cara Membuat Arang Sekam Padi. Diakses tanggal 22 April 2014. http://www.alamtani.com/arangsekam-padi.html,

Hambali, E., dkk., 2007. Teknologi Bioenergi. Biodiesel, Bioetanol, Biogas, Pure PlantOil, Biobriket dan Bio-Oil. Agromedia Pustaka. Jakarta.

Marsono dan Sigit, P., 2005. Pupuk Akar, Jenis dan Aplikasi. Penebar Swadaya. Jakarta.

Noor, M., 2001. Pertanian Lahan Gambut. Potensi dan Kendala. Kanisius. Yogyakarta

Sihaputar, D., 2012. Teknologi Briket Sekam Padi. Balai Pengkajian Teknologi Riau. http://riau.litbang.deptan.go.id/ind/images/st ories/PDF/teknologibriket.pdf Diakses Tanggal 22 April 2014.

Suji, M.S., 2014. Pengaruh Pemberian Bokashi Sekam Padi Berstimulator EM4 Terhadap Pertumbuhan dan Hasil Tanaman Jagung Manis (Zea mays Saccharata).Universitas Gorontalo.

Perda No. 6, $2008 . \quad$ Pemekaran Kecamatan Kertak Hanyar dan Pembentukan Kecamatan Tatah Makmur dalam Wilayah Kabupaten Banjar. 